\title{
Antidiabetic Activity of Blood Burnet Extract in High Fructose Fed Insulin Resistant Rats
}

\author{
Viktoriia Klevanova and Sergiy Trzhetsynskiy \\ Department of Pharmacognosy, Pharmacology and Botany, Zaporizhzhia State Medical University, Zaporizhzhia 69035, Ukraine
}

\begin{abstract}
Insulin resistance is one of leading pathogenic process in diabetes mellitus type-2. It is known that high-fructose intake leads to obesity, diabetes, dyslipidemia in rodents. The aim of our study was to evaluate the effect of Blood burnet's extract on body weight, visceral fat, blood glucose, plasma insulin, lipid profiles, lipid peroxidation and enzymatic antioxidants (superoxide dismutase, catalase, glutathione reductase) in fructose-induced type-2 diabetic rats. Our results showed that in high-fructose-induced diabetic rats were observed abdominal obesity, hyperglycemia, hyperinsulinemia, increased lipid profiles and atherogenic index, decreased insulin sensitivity, activation of lipid peroxidation and reduced activities of enzymatic antioxidants. Blood burnet's extract was able to improve insulin resistance, glucose toleration, rectifies dyslipidemia and abolish the damage in antioxidant system in terms of high-fructose feeding in rats.
\end{abstract}

Key words: Poterium sanguisorba L., blood burnet, insulin resistance, fructose, rats.

\section{Introduction}

About 347 million people worldwide have diabetes. In 2014, nine percent of adults 18 years and older had diabetes. There is an emerging global epidemic of diabetes that can be traced back to rapid increases in overweight, including obesity and physical inactivity. Diabetes is predicted to become the 7th leading cause of death in the world by the year 2030. In 2012 diabetes was the direct cause of 1.5 million deaths and total deaths from diabetes are projected to rise by more than $50 \%$ in the next 10 years $[1,2]$.

There are two major forms of diabetes: type 1 diabetes is characterized by a lack of insulin production and type 2 diabetes results from the body's ineffective use of insulin. Type 2 accounts for around $90 \%$ of all diabetes worldwide. Type 2 diabetes (formerly called non-insulin-dependent or adult-onset) comprises $90 \%$ of people with diabetes around the world, and is largely the result of excess body weight and physical inactivity. Impaired glucose tolerance and impaired fasting

\footnotetext{
Corresponding author: Viktoriia Klevanova, assistant, research field: pharmacology. E-mail address: kushugum@mail.ru.
}

glycaemia are intermediate conditions in the transition between normality and diabetes [1-3].

Plant materials have played an important role in the traditional treatment of diabetes, particularly the type 2 form. In many regions of the world, herbal remedies continue to be more accessible and affordable than conventional drugs and represent the first line of treatment available to a diabetes patient. Concurrently, within societies with well-developed, modern health care systems, demand is growing for herbal remedies to complement prescribed, modern therapies for many diseases, including diabetes [4].

Plant-based medicinal products have been known to man since ancient times. Plants have been the primary source of drugs, and many of the currently available drugs have been directly or indirectly derived from plants. Research suggests that using an antidiabetic plant in whole form or as complex extracts may offer many benefits due to the presence of multiple active components $[5,6]$.

Marles and Farnsworth estimated that more than 1000 plant species are being used as folk medicine for diabetes. Biological actions of the plant products used as alternative medicines to treat diabetes are related to 
their chemical composition. Herbal products or plant products are rich in phenolic compounds, flavonoids, terpenoids, coumarins, and other constituents which show reduction in blood glucose levels $[6,7]$.

It is often reported that such species of plants as Poterium ancistroides Guir. ex. Nym. and Poterium spinosum $L$. is used traditionally to treat diabetes in different parts of the world. Poterium spinosum $L$. is known in Bedouin medicinal folklore for its potent antidiabetic properties [4, 6, 7]. Hypoglycemic effect of Poterium ancistroides Guir. ex. Nym. and its triterpene compound tormentic acid was confirmed by many studies $[8,9]$.

Among mentioned plants of the genus Poterium L. only Poterium sanguisorba L. (Blood burnet) is widespread in Ukraine and, moreover, its hypoglycemic properties hardly been investigated. Sanguisorba minor Scop. (Poterium Sanguisorba L.), salad or garden burnet is a variable species of the Old World, is naturalized from Nova Scotia to Ontario south to North Carolina and Kentucky; it is locally adventive in Washington, Oregon, and California. Its indigenous range is from Scandinavia to northern Africa and the Canary Islands, eastward to southwestern and central Asia [10]. The common small or upland burnet has a perennial root, penetrating deep into the earth. Stems nearly upright, from nine inches to a foot high. The bottom leaves have seven or eight pairs of roundish leafless; the stem-leaves have five or six, or at top only two pairs of ovate-pointed leaflets. Flowers peduncled in little roundish heads; greenish, sometimes purplish on the outside, the terminating one largest: each head has male flowers below, and female or fertile flowers above, expanding before the former, which are frequently imperfect hermaphrodites. Native of England, Germany, Swifferland, in high dry pastures, in a calcareous soil; Cowering in May, and sometimes in April. The leaves, when bruited, smell like cucumber, and taste something like the paring of that fruit; they are sometimes put into salads and cool tankards [11].

Therefore, the aim of our work is to study antidiabetic activity of Blood burnet.

\section{Materials and Methods}

\subsection{Plant Material}

Blood burnet's rhizome was collected from the steppe zone in Zaporizhzhia region, Ukraine and identified by employees of M.G. Kholodny Institute of Botany NASU, Kyiv, Ukraine. The rhizomes were air dried under shade and powdered using mechanical grinder and stored in air-tight container.

\subsection{Preparation of Ethanolic Extract of Blood Burnet's Rhizome}

Dried, powdered rhizomes were extracted with ethanol using soxhlet apparatus for $72 \mathrm{hrs}$. The BBE (blood burnet's extract) was concentrated under vacuum evaporator and residue extract was stored at $4^{0} \mathrm{C}$ in refrigerator for further pharmacological studies.

\subsection{Animals}

Healthy male and female Wistar albino rats weighing 120-140 $\mathrm{g}$ were purchased from animal house of ZSMU (Zaporizhzhia State Medical University), Ukraine and were kept in cages with standard laboratory conditions (temperature $22 \pm 2{ }^{\circ} \mathrm{C}$ with a 12/12 hr light-dark cycle). The animals were fed with normal laboratory diet and allowed to drink water ad libitum. All researches were conducted with ethical standards in accordance to the rules of ICH (international conference on harmonisation) - GCP (good clinical practice), Declaration of Helsinki (1964), the European Convention on Human Rights and Biomedicine (ETS 164) and the Ukraine laws.

\subsection{Acute Toxicity Studies}

After the oral administration of BBE $5 \mathrm{~g} / \mathrm{kg}$, animals were observed individually atleast once during the first 30 minutes and periodically during the first 24 hours, with special attention given during the first 4 hours and daily thereafter, for total of 14 days. Observations included changes in skin and fur, eyes and mucous 
membranes, and also respiratory, circulatory, autonomic and central nervous systems, and somatomotor activity and behavior pattern. Observations of tremors, convulsions, salivation, diarrhea, lethargy, sleep and coma were recorded [12].

\subsection{Experimental Design for Hypoglycemic Activity}

The animals were divided into four groups $(n=6)$. Group I: intact control rats were administered distilled water; Group II, III and IV: rats received BBE orally by gastric tube in doses of 50,100 and $200 \mathrm{mg} / \mathrm{kg}$ body weight respectively; Group V: rats received gliclazide ( $50 \mathrm{mg} / \mathrm{kg}$ bodyweight, Sigma Aldrich, USA). All the animals were fasted over night before administration. The fasting blood glucose levels were measured with One Touch Select glucometer (Johnson and Johnson, USA) through lateral tail vein of rats at $0,2,4,6$ and 8 $\mathrm{h}$ after feeding [12].

\subsection{Experimental Design for Antidiabetic Activity}

Induction of insulin resistance by high fructose administration and treatment protocol: The experimental rats were divided into 5 groups $(\mathrm{n}=6)$. Group I: intact control rats, Group II, III, IV and V: received during 8 weeks $20 \%$ fructose solution instead of water $[13,14]$. During last two weeks the FF (fructose-fed) groups were also treated by: Group II: used as insulin resistant control group and received distilled water by gastric tube; Group III: rats received BBE orally by gastric tube in dose $100 \mathrm{mg} / \mathrm{kg}$ body weight; Group IV: rats received metformin $(150 \mathrm{mg} / \mathrm{kg}$ bodyweight, Aldrich, USA) as standard medication; Group V: rats received decoction of arfazetin, the one of the most widespread herbal collection, which consist from blueberries shoots, folds of beans fruits, devil's high rhizomes with roots, dog-rose fruit, horsetail herb, St. John's wort herb, chamomile flowers, in dose 10 $\mathrm{ml} / \mathrm{kg}$ as standard medication.

\subsection{Body Weight}

Body weight was measured weekly throughout the all term of each experiment.

\subsection{Glucose Tolerance Test}

Animals were loaded with glucose ( $3 \mathrm{~g} / \mathrm{kg}$ p.o.) and the blood samples were collected on $0,30,60,120$ minutes time interval [12]. The blood glucose levels were determined by using One Touch Select glucometer.

\subsection{Blood, Liver and Fat Collection}

At the end of the treatment period, all of the groups were fasted for $12 \mathrm{~h}$ and then anesthetised. The blood was collected into heparinised tubes and centrifuged at $4000 \mathrm{rpm}$ for $10 \mathrm{~min}$ at $4{ }^{\circ} \mathrm{C}$, and the serum was collected and stored at $-80^{\circ} \mathrm{C}$ until biochemical estimation was carried out or used for the assay of catalase level. The liver was dissected out into ice-cold saline, thoroughly rinsed and subjected to the antioxidant estimation and glycogen determination. The visceral fat was collected from abdomen than was weighed.

\subsection{Biochemical Analysis}

Serum TG (triglyceride), TC (total cholesterol), LDL-c (LDL-cholesterol) and HDL-c (HDL-cholesterol) were estimated using enzymatic methods (Felicit, Ukraine). Atherogenic Index was calculated using formula ((TC-HDL-c/HDL-c) $\times 100$ (\%)) [12]. Circulating insulin level was evaluated by radioimmunoassay.

HOMA-IR (homeostasis model assessment of insulin resistance) was calculated using the equation: (insulin $(\mu \mathrm{U} / \mathrm{mL}) \times$ glucose $(\mathrm{mmol} / \mathrm{L})) / 22.5$ [15]

Liver glycogen was estimated by the standard method [16]. The glycogen content in liver was expressed in $\mathrm{mg} \%$.

\subsection{Estimation of Antioxidant System}

Ten percent liver homogenate was prepared using ice-cold buffer for homogenization $(50 \mathrm{mM}$ Tris- $\mathrm{HCl}$, $2 \mathrm{mM}$ EDTA sodium salt and $2 \mathrm{mM}$ Triton $\mathrm{X}$ ) and then 
centrifuged at $12,000 \mathrm{rpm}$ for $15 \mathrm{~min}$. The supernatant was used for the estimation of oxidative stress markers and enzymatic antioxidants.

Lipid peroxidation expressed in terms of MDA (malondialdehyde) amount [17]. The enzymatic antioxidants such as GR (glutathione reductase), SOD (superoxide dismutase) were determined by standard methods [18, 19]. Total thiols were estimated by standard spectrophotometric assays [20]. The estimation of CAT (catalase) was carried in serum [21]. The concentration of antioxidant enzymes was expressed in terms of protein content in the liver homogenate. Total protein content was measured by biuret method (Felicit, Ukraine).

\subsection{Statistical Analysis}

All results were expressed by the equation mean \pm SEM. One-way ANOVA test was used for statistical analysis followed by Mann-Whitney $U$ test. Values of $P<0.05$ were considered to be statistically significant.

\section{Results}

\subsection{Body Weight and Visceral Fat}

There was no significant difference between the initial body weights of the study groups. After 8 weeks of fructose feeding was resulted a statistically different increase in the body weight of control group by $5.4 \%$ when compared to intact group. BBE was able to attenuate this effect because group received BBE was of a significantly less body weight than control group by $3.7 \%$ (Table 1, Fig. 1). There was no significant difference in body weight between arfazetin and control groups $(P<0.05)$.

The visceral fat weight of control group was significantly higher $(P<0.05)$ than of intact group by $30.7 \%$ respectively. The visceral fat weight in BBE, metformin and arfazetin groups have also a statistically difference from control group $(P<0.05)$.

\subsection{Oral Glucose Tolerance Test.}

The analysis of the OGTT at the end of the feeding period showed that FF developed glucose intolerance (Table 1, Fig. 2). The AUC (area under the curve) of glucose during OGTT of control group was significantly elevated by $27.2 \%$ when compared to intact group $(P<0.05)$. The AUC in BBE group was significantly lower than that of control group by $15.3 \%$ and was only elevated by $7.2 \%$ when compared to intact group and was not statistically different (Table 1, Fig. 2).

Table 1 Effect of BBE on insulin resistance related parameters antioxidants in terms of high fructose feeding.

\begin{tabular}{|c|c|c|c|c|c|}
\hline \multirow[t]{2}{*}{ Parameter } & \multicolumn{5}{|c|}{ Groups } \\
\hline & Intact & Control & $\mathrm{BBE}$ & Metformin & Arfazetin \\
\hline Initial weight $(\mathrm{g})$ & $125,50 \pm 1,231$ & $128,60 \pm 1,52$ & $128,50 \pm 1,454$ & $128,16 \pm 1,275$ & $129,83 \pm 1,351$ \\
\hline Weight after 6 weeks (g) & $154,16 \pm 1,447 *$ & $160,83 \pm 1,99$ & $158,83 \pm 3,646$ & $165,00 \pm 1,211^{\#}$ & $166,33 \pm 1,201^{\#}$ \\
\hline Weight after 8 weeks (g) & $169,33 \pm 2,06^{*}$ & $178,5 \pm 1,231$ & $172,16 \pm 1,492 *$ & $171,83 \pm 0,872 *$ & $173,66 \pm 1,584$ \\
\hline Visceral fat $(\mathrm{g})$ & $3,54 \pm 0,09 *$ & $5,12 \pm 0,043$ & $3,74 \pm 0,06^{*}$ & $2,86 \pm 0,04^{* \#}$ & $3,74 \pm 0,06^{* \#}$ \\
\hline Insulin $(\mu \mathrm{U} / \mathrm{mL})$ & $9,66 \pm 0,333^{*}$ & $14,83 \pm 0,366$ & $11,55 \pm 0,306^{* \#}$ & $9,73 \pm 0,423^{*}$ & $13,63 \pm 0,226^{* \#}$ \\
\hline Glucose (mmol/L) & $4,43 \pm 0,066^{*}$ & $5,03 \pm 0,076$ & $4,43 \pm 0,092 *$ & $4,30 \pm 0,068^{*}$ & $4,65 \pm 0,114^{*}$ \\
\hline HOMA-IR & $1,90 \pm 0,086^{*}$ & $3,32 \pm 0,124$ & $2,28 \pm 0,094 *^{\#}$ & $1,86 \pm 0,101^{*}$ & $2,81 \pm 0,062^{* \#}$ \\
\hline Glycogen content (mg \%) & $1977,3 \pm 49,6^{*}$ & $886,7 \pm 20,9$ & $3139,1 \pm 71,1$ *\# $^{\#}$ & $2176,2 \pm 75,8^{*}$ & $2473,4 \pm 28,8^{*^{\#}}$ \\
\hline $\operatorname{AUC}(\mathrm{mmol} / \mathrm{L} / \mathrm{min})$ & $955,8 \pm 16,46^{*}$ & $1215,7 \pm 15,80$ & $1030,2 \pm 28,94^{*}$ & $1010,2 \pm 16,42 *$ & $1024,4 \pm 19,97$ *\# $^{\#}$ \\
\hline Cholesterol (mmol/L) & $0,95 \pm 0,034^{*}$ & $1,25 \pm 0,034$ & $1,00 \pm 0,044^{*}$ & $1,15 \pm 0,034^{\#}$ & $1,18 \pm 0,065^{\#}$ \\
\hline Triglyceride (mmol/L) & $0,35 \pm 0,056^{*}$ & $0,78 \pm 0,047$ & $0,41 \pm 0,016^{*}$ & $0,50 \pm 0,036^{*}$ & $0,71 \pm 0,016^{\#}$ \\
\hline HDL-c (mmol/L) & $0,58 \pm 0,038^{*}$ & $0,46 \pm 0,021$ & $0,53 \pm 0,033$ & $0,63 \pm 0,021 *$ & $0,70 \pm 0,025^{* \#}$ \\
\hline LDL-c (mmol/L) & $0,35 \pm 0,046$ & $0,42 \pm 0,008$ & $0,15 \pm 0,013^{* \#}$ & $0,15 \pm 0,008^{* \#}$ & $0,14 \pm 0,008^{* \#}$ \\
\hline Atherogenic index & $2,05 \pm 0,087^{*}$ & $2,69 \pm 0,066$ & $1,89 \pm 0,071^{*}$ & $1,82 \pm 0,056^{*}$ & $1,68 \pm 0,058^{*}$ \\
\hline
\end{tabular}

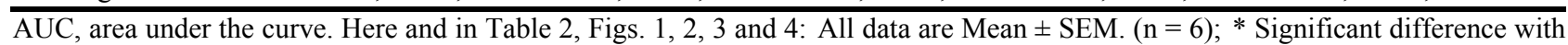
control group $(P<0.05)$; \# Significant difference with intact group $(P<0.05)$. 

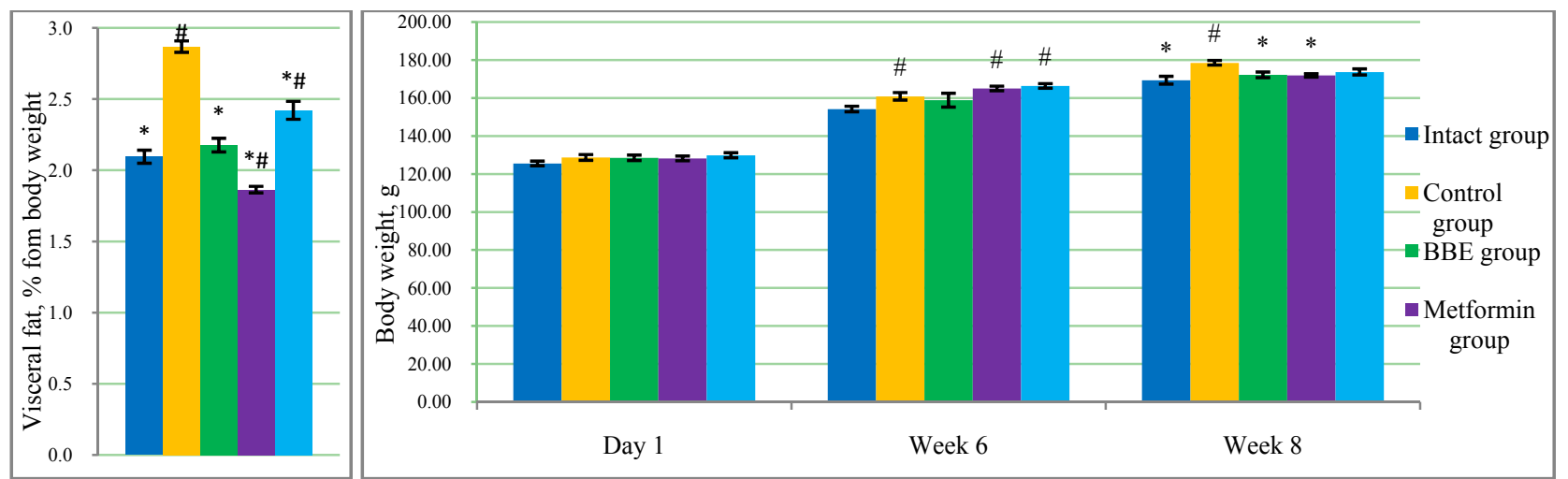

Fig. 1 Effect of BBE on body weight and visceral fat in FF rats.
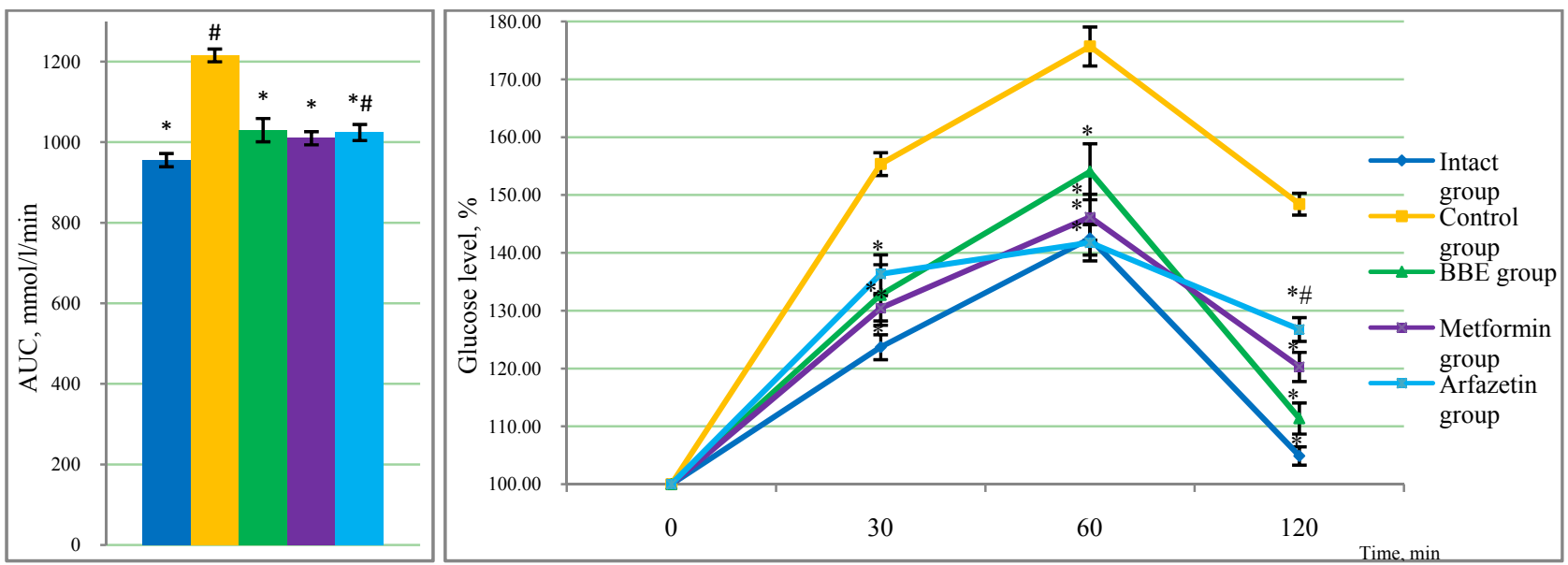

Fig. 2 Effect of BBE on glucose tolerance in FF rats.

3.3 Serum Level of Insulin, Blood Glucose and Homeostasis Model Assessment of Insulin Resistance

Serum level of insulin in BBE and arfazetin groups was significantly lower in comparison with the control group by $22.1 \%$ and $8.1 \%$ respectively $(P<0.05)$ but also it has a statistically different increase when compared to intact group. Blood glucose in BBE, metformin and arfazetin groups had significant difference with control group $(P<0.05)$.

The HOMA results of control group was 1.74 fold greater than those of intact group, and 1.46, 1.78 and 1.18 fold greater than those of BBE, metformin and arfazetin groups respectively. BBE and arfazetin groups showed a significant increase $(P<0.05)$ when compared to intact group (Table 1, Fig. 3).

\subsection{Liver Glycogen}

Control rats showed significantly decreased glycogen in liver by $55.2 \%$ when compared to intact group $(\mathrm{P}<0.05)$. Treatment with $\mathrm{BBE}$ significantly increased the liver glycogen content compared to that of control group by $71.8 \%$. Metformin and arfazetin also showed significantly increased levels of liver glycogen by $59.3 \%$ and $64.2 \%$ when compared to control group (Table 1, Fig. 4).

\subsection{Lipid Profile}

The serum TG and TC values were significantly increased by $123.7 \%$ and $31.6 \%$, and HDL-c was significantly decreased by $20.1 \%$ in control group, when compared to intact group. Treatment with BBE significantly normalized TG and TC levels (decrease by $46.9 \%$ and $20.0 \%$ respectively) when compared to control group $(P<0.05)$. Serum HDL-c concentrations of $\mathrm{BBE}$ group was higher by $14.4 \%$ than those of control group and lower by $8.6 \%$ when compared to 

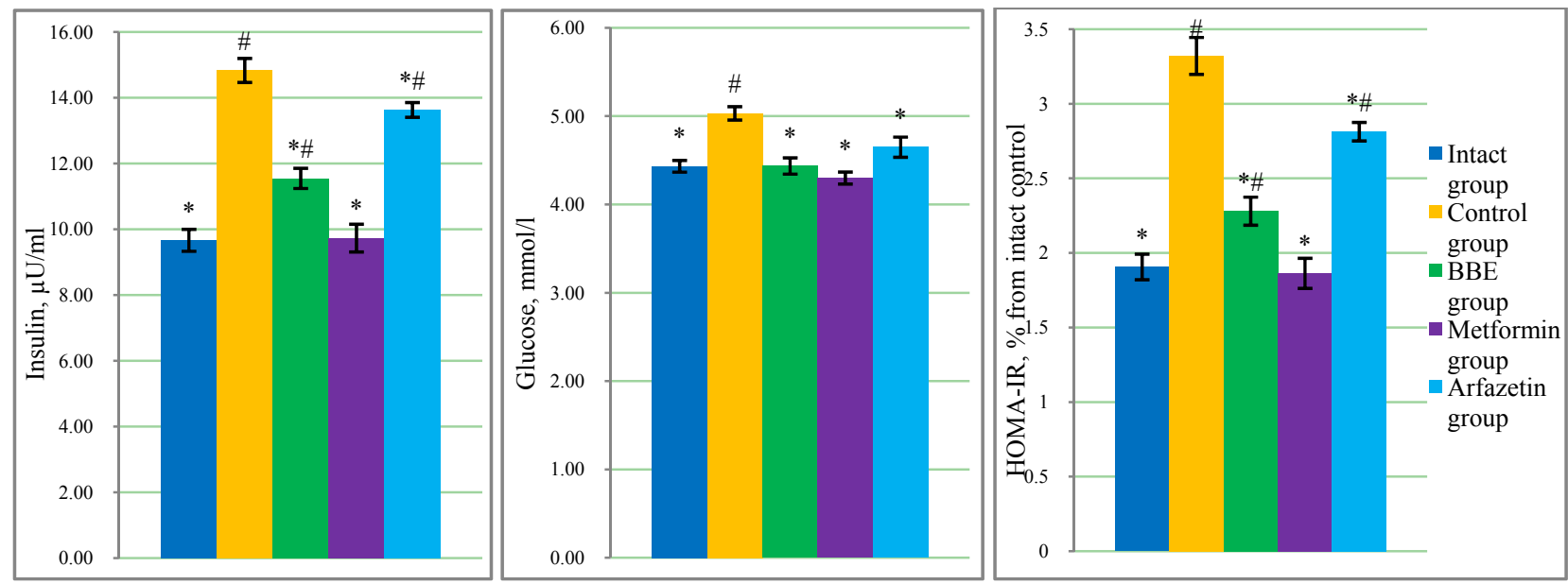

Fig. 3 Effect of BBE on serum level of insulin, blood glucose and HOMA in FF rats.

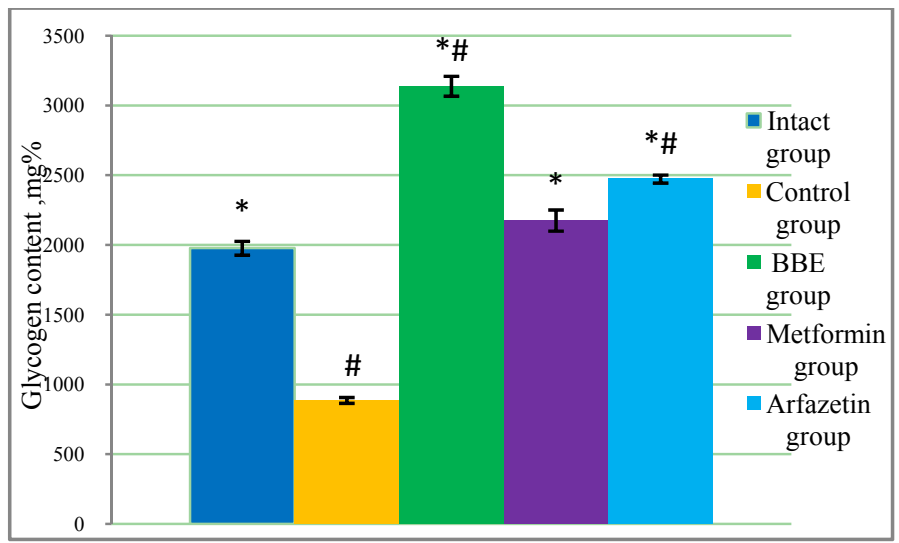

Fig. 4 Effect of BBE on glycogen content in FF rats.

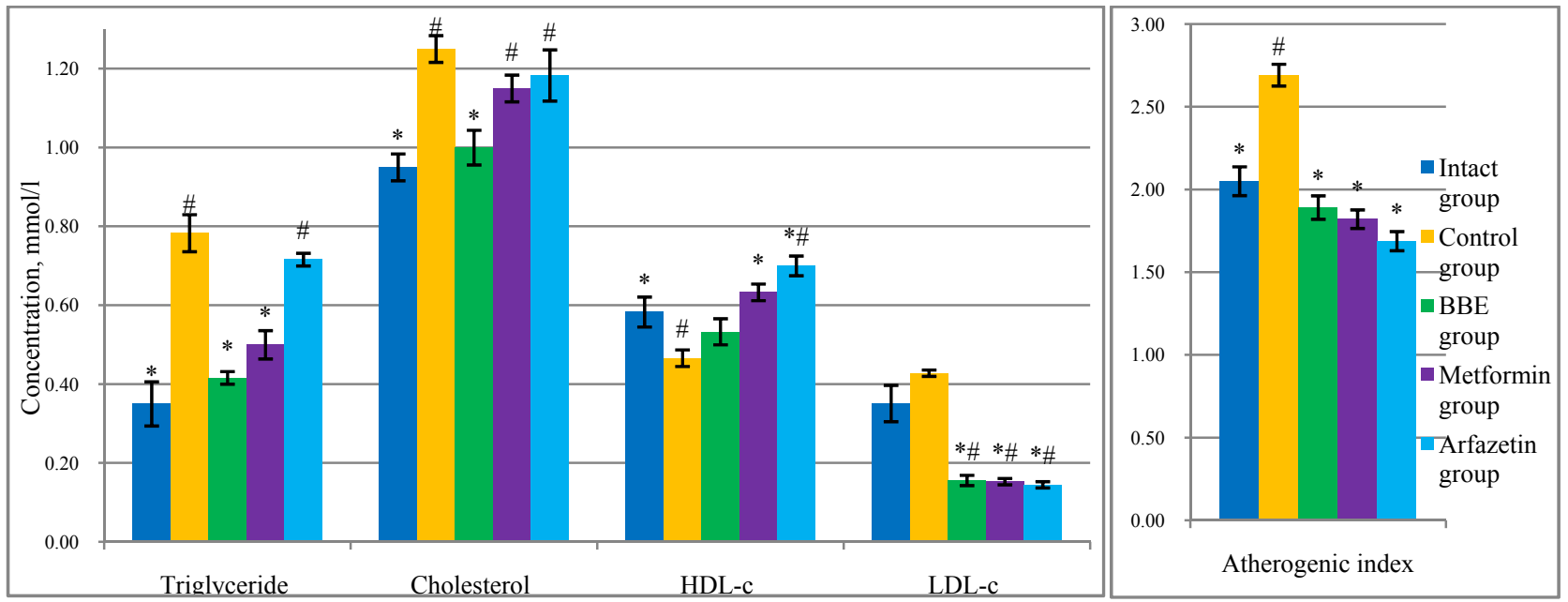

Fig. 5 Effect of BBE on lipid profile and atherogenic index in FF rats.

intact group but this results were not statistically different $(P<0.05)$. There was no significant difference in serum TG and TC levels of arfazetin group than those of control group but serum HDL-c concentration was significantly decreased by $20.1 \%$ when compared to intact group (Table 1, Fig. 5).

There was no significant difference in serum LDL-c between control and intact groups, while there was a 
significant decrease in BBE, metformin and arfazetin groups when compared to control and intact groups $(P$ $<0.05)$.

The atherogenic index of BBE, metformin and arfazetin groups was statistically lower when compared to control group $(P<0.05)$.

\subsection{Antioxidant System Parameters}

Control group showed significantly higher levels of MDA as compared with intact group by $34.6 \%$ ( $P<$ $0.05)$. Level of MDA of BBE group was significantly lower by $21.7 \%$ when compared with control group but still was higher than intact group. The activities of SOD, CAT and GR were significantly lower (36.5\%, $50.5 \%$ and $52.0 \%$ respectively) in control rats than in intact rats, but treatment with BBE restored activities of this enzymes by $36.3 \%, 44.6 \%$ and $40.9 \%$ respectively when compared with control group. The level of TT in FF rats were statistically $(P<0.05)$ reduced when compared to intact rats by $38.6 \%$. In BBE group the levels of TT was significantly higher by $22.3 \%$ when compared with control group (Table 2, Fig. $6)$.

\section{Discussion}

It has been established that insulin resistance, impaired glucose tolerance, hyperinsulinemia, hypertension and hyperlipidemia are associated with fructose intake in animal models. Increasing the dietary fructose consumption might be one of the factors responsible for the development of obesity and the accompanying insulin resistance syndrome. Also, several studies have demonstrated that chronic high-fructose feeding leads to insulin resistance, glucose

Table 2 Effect of BBE on hepatic oxidative stress markers and antioxidants in terms of high fructose feeding.

\begin{tabular}{|c|c|c|c|c|c|}
\hline \multirow[t]{2}{*}{ Parameter } & \multicolumn{5}{|c|}{ Groups } \\
\hline & Intact & Control & $\mathrm{BBE}$ & Metformin & Arfazetin \\
\hline $\begin{array}{l}\text { MDA } \\
\text { (mmol/g of tissue) }\end{array}$ & $14,17 \pm 0,50^{*}$ & $21,68 \pm 0,49$ & $17,00 \pm 0,29^{* \#}$ & $17,66 \pm 0,47^{* \#}$ & $18,63 \pm 0,55^{* \#}$ \\
\hline $\begin{array}{l}\text { GR } \\
(\mu \mathrm{mol} \text { NADH} / \mathrm{min} / \mathrm{mg} \text { protein })\end{array}$ & $17,81 \pm 0,92^{*}$ & $8,54 \pm 0,52$ & $14,46 \pm 0,37^{* \#}$ & $11,79 \pm 0,37^{* \#}$ & $11,92 \pm 0,46^{* \#}$ \\
\hline $\begin{array}{l}\text { TT } \\
(\mu \mathrm{mol} / \mathrm{mg} \text { protein })\end{array}$ & $68,74 \pm 2,55^{*}$ & $42,20 \pm 1,01$ & $54,34 \pm 2,19^{* \#}$ & $52,78 \pm 2,01^{* \#}$ & $51,56 \pm 1,12^{* \sharp}$ \\
\hline $\begin{array}{l}\text { SOD } \\
\text { (units/mg protein } / \mathrm{min} \text { ) }\end{array}$ & $48,17 \pm 1,52^{*}$ & $30,57 \pm 1,40$ & $48,02 \pm 2,07^{*}$ & $37,01 \pm 1,76^{* \#}$ & $39,67 \pm 1,80^{* \#}$ \\
\hline $\begin{array}{l}\text { CAT } \\
\text { (mcat } / \mathrm{mL} * \min )\end{array}$ & $11,13 \pm 0,21^{*}$ & $5,51 \pm 0,33$ & $9,96 \pm 0,25^{* \#}$ & $9,28 \pm 0,27^{* \#}$ & $8,38 \pm 0,23^{* \#}$ \\
\hline
\end{tabular}

(mcat $\left./ \mathrm{mL}^{*} \min \right)$

* Significant difference with control group $(P<0.05)$;

\# Significant difference with intact group $(P<0.05)$.

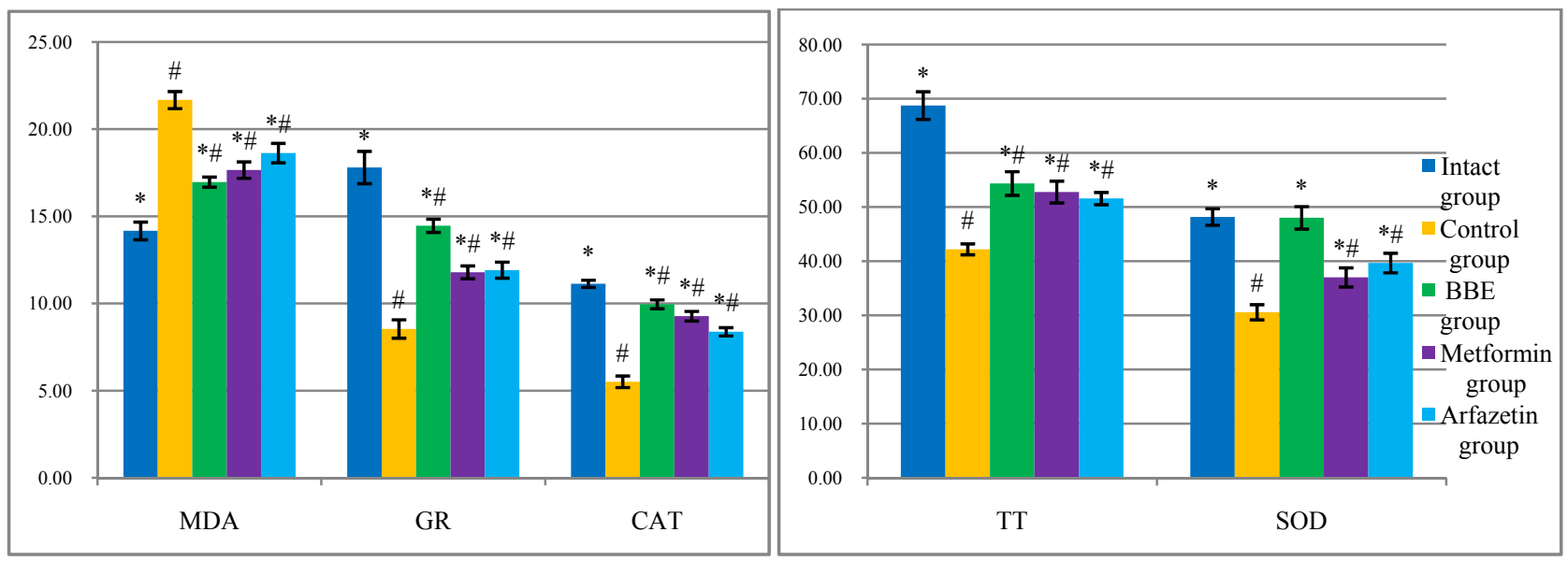

Fig. 6 Effect of BBE on hepatic oxidative stress markers and antioxidants in FF rats.

MDA: $\mathrm{mmol} / \mathrm{g}$ of tissue, GR: $\mu \mathrm{mol} \mathrm{NADH} / \mathrm{min} / \mathrm{mg}$ protein, TT: $\mu \mathrm{mol} / \mathrm{mg}$ protein, SOD: units/mg protein/min, CAT: $\mathrm{mcat} / \mathrm{mL} * \mathrm{~min}$. 
intolerance, hyperinsulinemia and hypertriglyceridemia in a relatively short time in normal rats. Thus, the rats received fructose-rich water could be served as a model for the investigation of insulin resistance [22-24].

In our study, FF animals showed significantly decreased insulin sensitivity associated with hyperglycemia and hyperinsulinemia. Enhanced insulin resistance was also reflected by HOMA.

It is known that an increased plasma triglyceride concentration is the expected consequence of insulin resistance [25]. In our study high-fructose feeding causes metabolic dyslipidemia with high levels of TG, TC, LDL-c and decreased level of HDL-c, which was confirmed with high atherogenic index. In addition, our results showed that FF rats had higher body weight to our mind related with visceral fat increased accumulation which in turn promotes insulin resistance.

In our study BBE treatment in FF rats improves metabolic disorders, has beneficial effect on insulin resistance and increased the insulin sensitivity in FF insulin resistant rats. The effect of $\mathrm{BBE}$ on these parameters was comparable with metformin prevention.

BBE has shown protection against hyperglycemia, hyperinsulinemia and elevated HOMA in FF rats.

Due to insulin resistance induced by fructose feeding there was depletion of glycogen content in liver in control group. Treatment with BBE prevented this in FF rats.

Content of visceral fat which is tightly related with insulin resistance improvement [26] decreased significantly in BBE treated rats in comparison with control group. According to this we associate BBE body weight lowering effect.

BBE attenuates the elevated AUC of the OGTT comparing to control rats and shows an ability to improve glucose tolerance.

Our study revealed significant alteration in the lipid profile in BBE treated group compared with FF group which indicated hypolipidemic effect of BBE. Treatment with BBE rectifies dyslipidemia observed in FF rats. Although BBE did not increase the fasting HDL-c level closely to metformin treated rats, it was able to attenuate the elevated TG and TC even better, and LDL-c closely to metformin treated rats. Furthermore it greatly improved the elevated atherogenic index.

It has been reported that insulin resistance induced by high-fructose diet in rats associated with oxidative stress [27]. High fructose-feeding increases lipid peroxidation in liver and our results confirms this due to increased level of MDA in control group. Administration of BBE significantly decreased the levels of MDA as well as metformin and arfazetin treated groups. Treatment with BBE also limited the depletion of TT and improves the activity of GR in liver compared with control group.

In fructose-fed rats observed the reduction in the activity of SOD and CAT which leads to the accumulation of superoxide anion radicals and hydrogen peroxide connected with a number of deleterious effects [22]. BBE treatment increased the activity of SOD and CAT in fructose-fed rats which would exert a beneficial action against pathological alterations caused by the presence of the free radicals.

The results clearly show that $\mathrm{BBE}$ treatment improves antioxidant protection and resist oxidative damages in terms of high fructose feeding.

\section{Conclusion}

In conclusion, the present study has demonstrated that oral administration of BBE guard against fructose-induced hyperglycemia, hypertriglyceridemia, hyperinsulinemia, improving insulin resistance and glucose tolerance in FF rats. Our results demonstrate that BBE supplementation is able to improve dyslipidemia and prevent increasing atherogenic index under high-fructose feeding in rats. Also our results verify antioxidant properties of BBE in vivo. 


\section{References}

[1] World Health Organization. 2015. "Media Centre. Diabetes. Fact Sheet N 312." Accessed January 2015. http://www.who.int/mediacentre/factsheets/fs312/en/.

[2] World Health Organization. 2012. "Global Status Report on Noncommunicable Diseases 2014. Geneva”. Accessed January 2015.

http://www.era-edta.org/ekha/WHO_Global_Status_Repo rt_on_NCDs_2014.pdf.

[3] World Health Organization. 2015. "10 facts about diabetes". Accessed November 2014.

http://www.who.int/features/factfiles/diabetes/facts/en/.

[4] Soumyanath, Amala. 2006. Traditional Medicines for Modern Times: Antidiabetic Plants. USA: CRC Press Taylor and Francis Group.

[5] Srinivasa, Rao Mentreddy. 2007. "Medicinal Plant Species with Potential Antidiabetic Properties." Journal of the Science of Food and Agriculture 87: 743-50.

[6] Upendra Rao, M., Sreenivasulu, M., Chengaiah, B., Jaganmohan Reddy, K., and Madhusudhana Chetty, C. 1892. "Herbal Medicines for Diabetes Mellitus." International Journal of Pharm. Tech. Research 2 (3):1883-98.

[7] Marlesa, R., and Farnsworthb, J. R. 1995. "Antidiabetic Plants and Their Active Constituents" Phytomedicine 2 (2): 137-89.

[8] Villar, A., Payá, M., Hortigüela, M. D., and Cortes, D. 1986. "Tormentic Acid, a New Hypoglycemic Agent from Poterium Ancistroides.” Planta Med. 52 (1): 43-5.

[9] Ivorra, M. D., Paya, M., and Villar, A. 1989. "Effect of Tormentic Acid on Insulin Secretion in Isolated Rat Islets of Langerhans." Phytotherapy Research 3 (4): 145-7.

[10] Kenneth Robertson, R. 1974. "The Genera of Rosaceae in the Southeastern United States." Journal of the Arnold Arboretum 55 (3): 398.

[11] Wilkes, J. 1826. Encyclopaedia Londinensis. London: R. G. Gunnell and Co, 21.

[12] Stefanov, A. V. 2002. Preclinical Studies of Drugs. Kyiv: Avitsenna. (in Ukrainian)

[13] Levi, B., and Werman, M. 1998. "Long Term Fructose Consumption Accelerates Glycation and Several Agerelated Variables in Male Rats." J. Nutrition 128: 1442-9.

[14] Bezerra, R. M., Ueno, M., Silva, M. S. Tavares, D. Q., Carvalho, C. R., and Saad, M. J. 2000. "A High Fructose Diet Affects the Early Steps of Insulin Action in Muscle and Liver of Rats.” J. Nutrition 130 (10): 1531-5.
[15] Matthews, D. R., Hosker, J. P., Rudenski, A. S. Naylor, B. A., Treacher, D. F., and Turner, R. C. 1985. "Homeostasis Model Assessment: Insulin Resistance and $\beta$-cell Function from Fasting Plasma Glucose and Insulin.” Diabetol 28: 412-9.

[16] Prokhorova, M. I., and Tulikov, S. N. 1965. Big Workshop on Carbohydrate and Lipid Metabolism. Leningrad: Leningrad University Press. (in Russian)

[17] Konyukhov, S. G., Markin, A. A., and Fedorov, T. N. 1989. "Lipid Peroxide Oxidation and Definitions Methods of Its Products in Biological Environments." Laboratory Case 9: 40-6. (in Russian)

[18] Beutler, E. 1984. Red Cell Metabolism. A Manual of Biochemical Methods. Orlando: Fl. Gune and Stratton inc.

[19] Chevari, C., and Csaba, I. 1998. "The Role of Superoxide Dismutase in Oxidative Processes Cells and the Method of Its Determination in Biological Materials." Laboratory case 11: 678-1. (in Russian)

[20] Halliwell, B. 1995. Free Radical in Biology and Medicine. Oxpord: Clarendon Press.

[21] Koroljuk, M. A., and Ivanova, L. I. 1998. "The Method of Determining Catalase Activity.” Laboratory Case 1: 16-9. (in Russian)

[22] Rajendra M., Badal, D., Badal, P., Badal, A., Khare, S., Jyoti, and Kumar, V. 2011. "Pharmacological Action of Mentha Piperita on Lipid Profile in Fructose-Fed Rats." Iranian Journal of Pharmaceutical Research 10 (4): 843-8.

[23] Rames, B., and Saralakumari, D. 2012. "Antihyperglycemic, Hypolipidemic and Antioxidant Activities of Ethanolic Extract of Commiphora Mukul Gum Resin in Fructose-Fed Male Wistar Rats.” J. Physiol. Biochem. 68: 573-82.

[24] Abbas, M., Ahmad, G., and Hossein, F. 2014. "Zataria Multiflora Increases Insulin Sensitivity and PPAR $\gamma$ Gene Expression in High Fructose Fed Insulin Resistant Rats." Iran J. Basic. Med. Sci. 17 (4): 263-70.

[25] Reaven, M.G., Twersk, J., and Chang, H. 1991. "Abnormalities of Carbohydrate and Lipid Metabolism in Dahl Rats.” Hypertens 18: 630-5.

[26] Tappy, L., Le, K. A., Tran, C., and Paquot, N. 2010. "Fructose and Metabolic Diseases: New Findings, New Questions." Nutrition 26 (11-12): 1044-9.

[27] Sandrine, D., Eleni, P., Richard, M., Caroline, A., Theophile, D., Jean-Paul, C., Gerard, C., and Jacqueline, A. 2005. "Involvement of Oxidative Stress and NADPH Oxidase Activation in the Development of Cardiovascular Complications in a Model of Insulin Resistance, the Fructose-Fed Rats.” Atherosclerosis 179: 43-9. 